INRA Prod. Anim., 2008, 21 (3), 239-250

\title{
Ecosystème caecal et nutrition du lapin : interactions avec la santé digestive
}

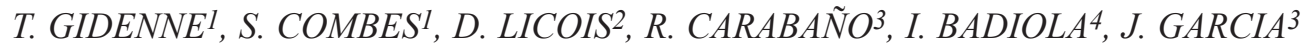 \\ ${ }^{1}$ INRA, Université de Toulouse INPT-ENSAT, ENVT, UMR 1289 Tissus Animaux, Nutrition, Digestion, \\ Ecosystème et Métabolisme, F-31326 Castanet-Tolosan, France \\ 2 INRA, UR 1282 Infectiologie Animale et Santé Publique, F- 37380 Nouzilly, France \\ ${ }^{3}$ Dpt de Producción Animal, ETSI Agronómos, Univ. Politécnica de Madrid, Ciudad Universitaria, \\ 28040 Madrid, Espagne \\ ${ }^{4}$ CreSA, Uab-IRTA, Campus de Bellaterra, Edifici V, 08193 Bellaterra, Barcelona, Espagne \\ Courriel : thierry.gidenne@toulouse.inra.fr
}

Le lapin tire parti de la symbiose avec le microbiote caeco-colique par deux voies. D'une part, comme chez tous les herbivores, la dégradation par les microorganismes des substrats entrant dans le caecum conduit à une production importante d'acides gras volatils, qui après leur absorption par la paroi caecale constituent une source d'énergie appréciable. D'autre part, le lapin présente la particularité de pratiquer la caecotrophie, et donc de recycler une partie du contenu caecal, riche en protéines bactériennes. Cet écosystème joue aussi un rôle dans la santé digestive de l'animal, en intervenant directement dans le rôle de flore barrière, et indirectement sur le statut immunitaire (Fortun Lamothe et Boullier 2007). L'étude du fonctionnement de cet écosystème est donc essentielle pour comprendre la physiopathologie digestive de cet animal, et améliorer les stratégies de nutrition et d'élevage.

Le biotope correspond à l'environnement (ou milieu), et la biocénose à l'ensemble des organismes vivant dans cet environnement. Les interactions entre un biotope et une biocénose définissent un écosystème. Appliqué au caecum du lapin, le biotope est donc l'organe luimême et son contenu, qui peuvent être analysés par des paramètres morphologiques (volume digestif, histologie de la muqueuse...), physiques (température, $\mathrm{pH}$, matière sèche, viscosité, oxygène...) ou biochimiques (acides organiques, protéines, enzymes...). Le biotope caecal a fait l'objet de nombreuses études, quoique certains paramètres demeurent toujours peu connus, tels le potentiel redox (Eh) ou la production de gaz $\left(\mathrm{H}_{2}, \mathrm{CO}_{2}, \mathrm{CH}_{4}\right)$. En revanche, la biocénose caecale a été moins étudiée, sachant que les méthodes classiques d'analyse (culture in vitro) sont laborieuses et n'identifient qu'une partie du microbiote digestif.

Les relations entre biotope caecal et biocénose demeurent donc faiblement décrites. Toutefois, depuis quelques années, cette thématique apparaît comme une priorité, pour mettre au point de nouvelles stratégies d'amélioration de la résistance du lapereau aux troubles digestifs. Ainsi, l'effet favorable des fibres sur la prévention des diarrhées du lapin après son sevrage a été démontré (Gidenne 2003), même face à un colibacille entéropathogène (Gidenne et Licois 2005). Ceci suggère un rôle important de l'écosystème caecal dans la prévention des diarrhées, puisque les fibres sont un substrat important pour le microbiote caecal. En revanche chez le lapin adulte, les perturbations digestives restent rares, même dans le cas d'une déficience en fibres ou face à un pathogène (Licois et al 1992). On peut avancer deux hypothèses (non exclusives) pour expliquer la sensibilité aux troubles digestifs chez le lapereau : 1) une implication de la maturation digestive, et notamment l'implantation du microbiote, dans la résistance aux microbes pathogènes (Padilha et al 1995) et qui correspond au concept de «flore de barrière» ; 2) la maturation du système immunitaire en interaction avec le microbiote (FortunLamothe et Boullier 2007). L'utilisation d'outils de microbiologie moléculaire devrait permettre d'améliorer nos connaissances sur le microbiote caecal et sur ses facteurs de contrôle et d'étudier ces deux hypothèses. Il s'agira de mieux comprendre les interac- tions entre la santé digestive de l'animal et la stabilité de l'écosystème caecal, ainsi que les relations avec la biodiversité de la biocénose.

Cette revue a donc pour objectif de rappeler quelques bases sur le biotope et la biocénose caecale du lapin domestique, puis de présenter comment il est possible de contrôler l'activité du microbiote, avec pour objectifs l'amélioration de la santé digestive du lapin en croissance et de sa digestion microbienne.

\section{1 / L'écosystème caecal du lapin}

\section{1 / Le biotope caecal}

Le contenu du caecum s'accroît linéairement de 2 à 5 semaines d'âge, et devient le plus grand compartiment digestif vers 5-6 semaines d'âge (40\% de la masse digestive). Sa teneur en matière sèche, faible à 2 semaines d'âge (12-15\%), atteint $23-26 \%$ la semaine suivante et se stabilise entre 21 et $23 \%$ à partir de $35 \mathrm{j}$ d'âge. A la naissance, les muqueuses caecales et coliques présentent des villosités, qui évoluent sous formes de «sillons» à partir de $16 \mathrm{j}$ d'âge (Yu et Chiou 1997, Sabatakou et al 1999), lorsque l'activité fermentaire se développe (figure 1). Cette dernière, a été identifiée chez le lapin pour la première fois en 1946 par Elsden et al puis l'activité cellulolytique des microorganismes hébergés dans le caecum a été montrée in vitro par Cools et Jeuniaux en 1961. Emaldi et al (1979) ont décrit l'activité métabolique du microbiote, soit l'hydrolyse de sub- 
Figure 1. Evolution de l'activité fermentaire caecale chez le lapereau.

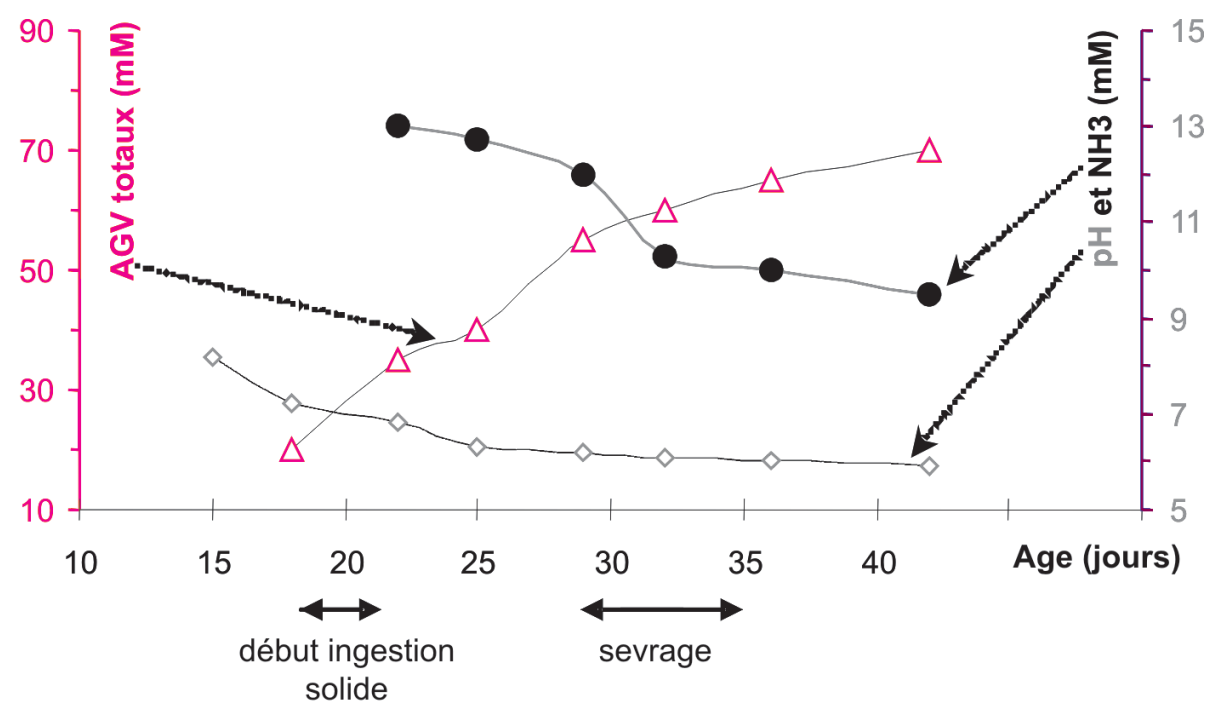

strats : urée, protéines, fibres, etc. On observe ainsi une uréolyse importante dans le caecum (Crociani et al 1984, Forsythe et Parker 1985). L'activité fibrolytique, spécifique des bactéries n'est pas détectable avant 2 semaines d'âge (Jehl et al 1995), mais elle s'accroît rapidement dès que le lapereau ingère des aliments solides (17-21 j), et dès 4 semaines d'âge elle est atteint $80 \%$ du niveau de l'adulte (figure 2, cf. $\S 1.2 a)$. L'activité pectinolytique et xylanolytique sont présentes dès $21 \mathrm{j}$ et triplent entre 21 et $35 \mathrm{j}$ (sevrage), tandis que l'activité cellulolytique demeure faible. Cette hiérarchie entre enzymes fibrolytiques (Pectinase > Xylanase $>$ Cellulase) est cohérente avec la digestion des principaux constituants glucidiques des parois végétales (pectines $>$ hémicelluloses $>$ cellulose).

La dégradation des nutriments par les microorganismes digestifs (figure 3) aboutit à la production de nombreux composés, dont les principaux sont des gaz $\left(\mathrm{CO}_{2}, \mathrm{CH}_{4}, \mathrm{H}_{2}\right)$, les Acides Gras

Figure 2. Chez le lapereau, l'activité fibrolytique des bactéries caecales s'accroît rapidement dès l'ingestion d'aliment solide.

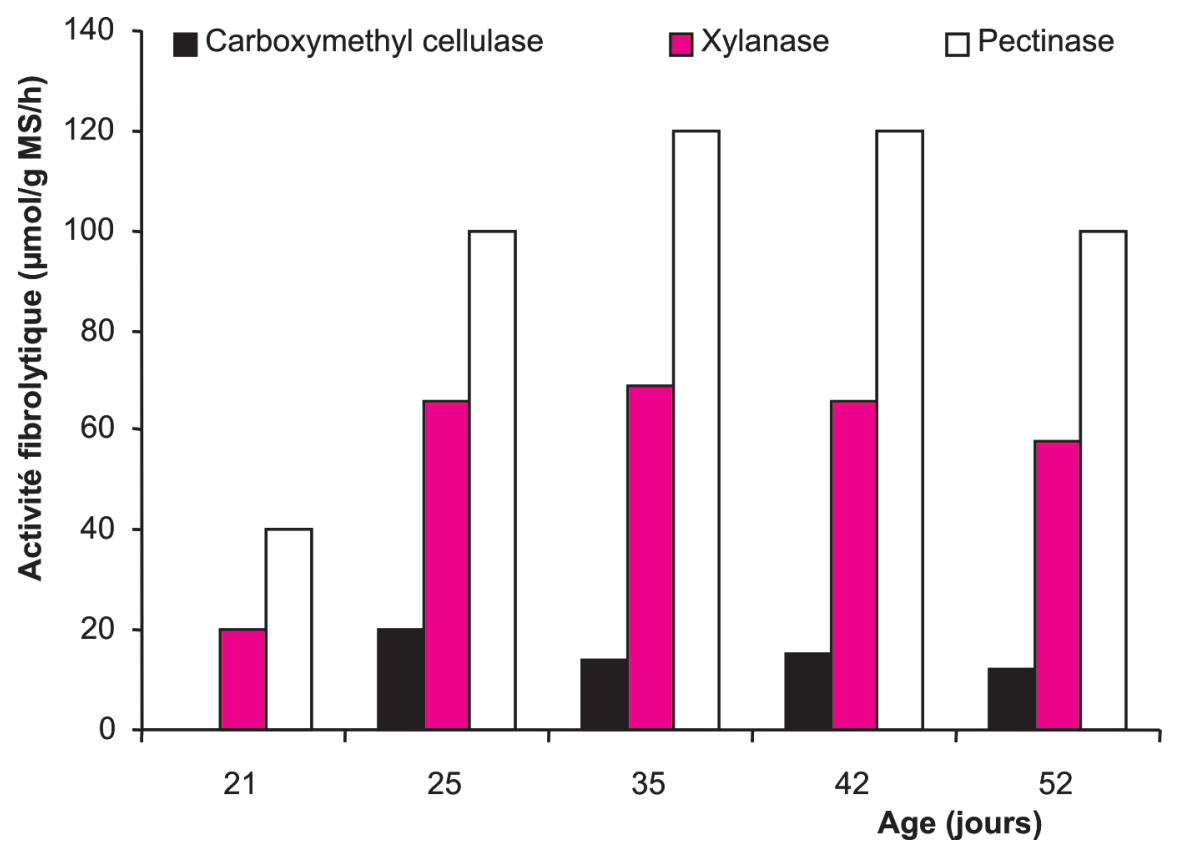

17-21 j : début de l'ingestion d'aliment solide.

Volatils (AGV), l'ammoniaque $\left(\mathrm{NH}_{3}\right)$. Ces deux derniers composés sont absorbés en quasi-totalité par la paroi caecale ; ainsi les AGV peuvent couvrir de 30 à $50 \%$ des besoins énergétiques d'entretien du lapin adulte (Gidenne 1994). Dès que l'animal ingère de l'aliment solide, vers 18 j d'âge, la concentration caecale en AGV augmente progressivement (20 à $70 \mathrm{mM}$, figure 1), celle de l'ammoniaque baisse légèrement, entraînant ainsi une baisse progressive du $\mathrm{pH}$. Une première étude $\mathrm{du}$ potentiel redox caecal (Kimse et al, 2007) indique une valeur moyenne de $230 \mathrm{mV}$, ce qui révèle un milieu plus réducteur (et donc plus anaérobie) que le rumen (- 150 à - $220 \mathrm{mV})$. Avec l'âge, la concentration en butyrate s'élève, tandis que celle du propionate est globalement stable ; le ratio propionate/butyrate devient donc inférieur à 1 après 25-30 j d'âge. Chez l'adulte, le profil fermentaire est dominé par l'acétate $(\mathrm{C} 2=60$ à $80 \%)$, suivi du butyrate $(\mathrm{C} 4=8$ à $20 \%)$ et enfin du propionate $(\mathrm{C} 3=3$ à $10 \%)$. Ainsi, contrairement à la plupart des herbivores d'élevage, le ratio $\mathrm{C} 3: \mathrm{C} 4$ est inférieur à 1 , en raison des caractéristiques du microbiote (Adjiri et al 1992).

Concernant les gaz de fermentations, une étude in vitro estime que l'activité méthanogénique est environ nulle jusqu'à $28 \mathrm{j}$ (sevrage), puis augmente après $36 \mathrm{j}$ d'âge (Piattoni et al 1996). Ceci suggérerait qu'aucun microorganisme méthanogénique ne se développe avant le sevrage, or il a été montré récemment que les archaea (connues pour produire le méthane) sont prédominantes avant le sevrage, comparées aux bactéries (Bennegadi et al 2003). Ceci souligne donc la nécessité d'études in vivo pour résoudre cette contradiction.

\section{2 / La biocénose caecale}

Le microbiote intestinal reste relativement mal connu, car il possède une grande biodiversité et de nombreux microorganismes demeurent non cultivables. Chez l'homme, le tube digestif «héberge» de l'ordre de $10^{14}$ bactéries, qui appartiendraient à plus de 400 espèces différentes, et dont la quasi-totalité serait de type anaérobie (99\%). De plus, environ 70 à $80 \%$ de cette biomasse microbienne serait non cultivable (Suau et al 1999).

Nos connaissances sur la colonisation $\mathrm{du}$ tube digestif du lapin sont encore très limitées. Elles ont été principalement obtenues par les techniques de culture (Gouet et Fonty 1973), qui 
Figure 3. Métabolisme caecal des principaux nutriments et formation des produits terminaux de la fermentation microbienne.

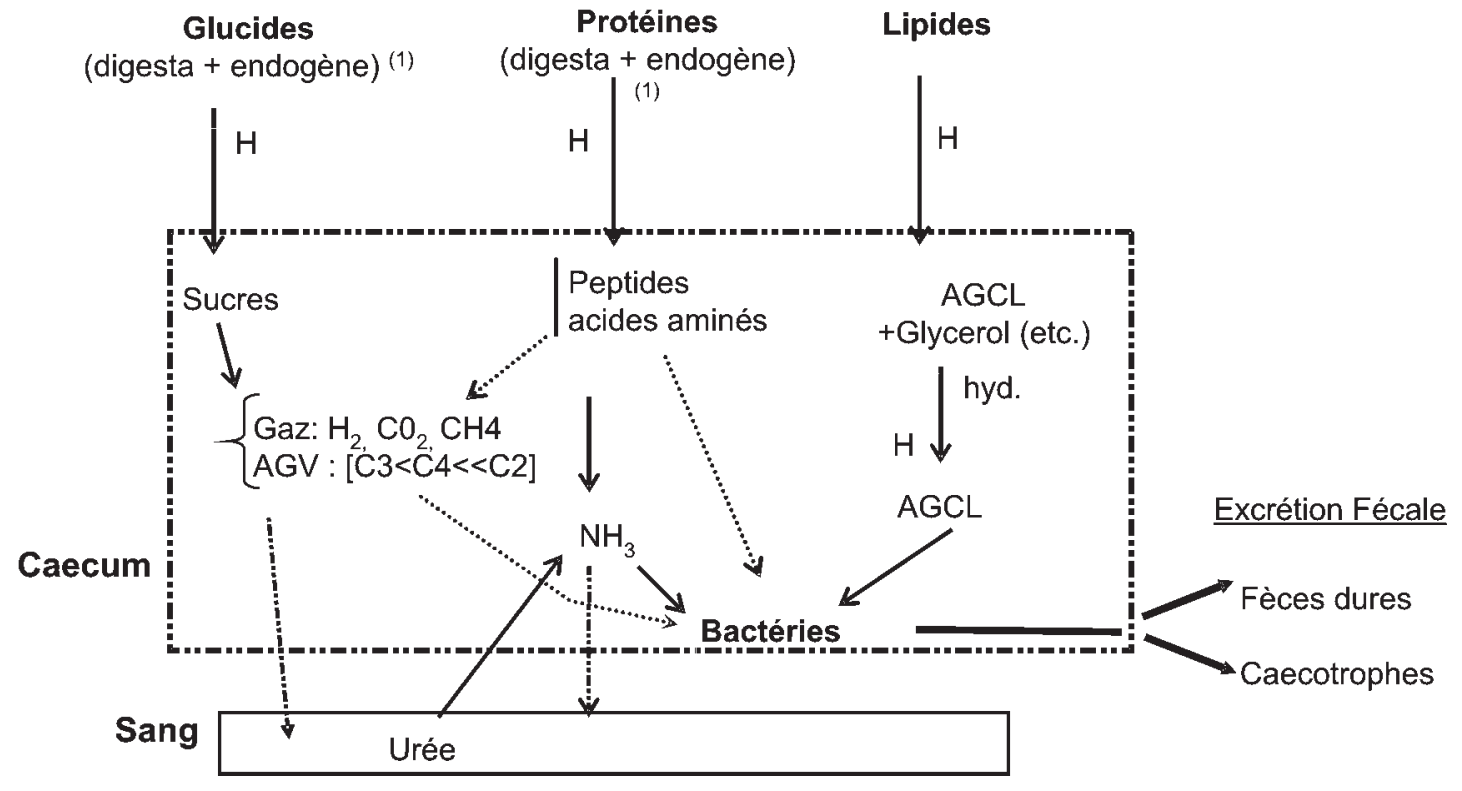

(1) digesta $=$ nutriments d'origine alimentaire (amidon, fibres...)

endogène $=$ polyosides du mucus, cellules épithéliales desquamées, protéines enzymatiques, etc. $\mathrm{H}=$ hydrolyse de polymère.

hyd. = Hydrogénation des Acides Gras à Chaines Longues (AGCL).

AGV = Acides Gras Volatils (C2=acétate ; C3=propionate ; C4=butyrate).

$\mathrm{NH}_{3}=$ ammoniaque.

dénombrent les colonies bactériennes se développant sur un substrat artificiel, par exemple : papier de cellulose pour estimer le nombre de bactéries «cellulolytiques». Récemment, grâce aux techniques de microbiologie moléculaire, de nombreuses espèces bactériennes non cultivables ont été mises en évidence chez le lapin (Abecia et al 2005a, Cauquil et al 2007), ainsi que des archaea (Bennegadi et al 2003, Michelland et al 2008a). Contrairement au rumen, la biocénose caecale du lapin ne contiendrait ni protozoaires, ni champignons anaérobies (Bennegadi et al 2003). La présence de levures dans le contenu caecal a été peu étudiée, mais au moins une espèce de levure (Saccharomycopsis guttulatus) semblerait «commensale» du caecum de lapin (Peeters et Maertens 1988), et se multiplierait plus activement lors de problèmes intestinaux (Licois données non publiées).

Nous présentons ici essentiellement des données du microbiote caecal, sachant que la colonisation des différents segments digestifs du lapin par les microorganismes a fait l'objet d'une synthèse récente (Carabaño et al 2006).

a) Analyse de la biocénose caecale par les méthodes classiques de culture

La cinétique d'implantation du microbiote dans le caecum du lapin a fait l'objet d'un faible nombre d'études. La colonisation du caecum débute chez le lapereau âgé de 2 ou 3 j, le nombre de bactéries varie considérablement selon les individus (Gouet et Fonty 1973) ; sachant que jusqu'à la fin de la première semaine de vie, la partie antérieure du tube digestif (estomac et intestin grêle) du lapereau est pratiquement stérile, contrairement à d'autres mammifères monogastriques (porc, rat, souris). A la fin de la première semaine postnatale le caecum héberge de $10^{7}$ à $10^{9}$ bactéries/g de contenu, puis passe à $10^{9}-10^{10}$ bactéries/g au cours de la seconde semaine de vie avec de faibles variations interindividuelles. Pendant toute cette période, le nombre de bactéries anaérobies facultatives est parfois équivalent à celui des anaérobies strictes. Dès la troisième semaine de vie, les bactéries anaérobies facultatives chutent $\left(10^{2}-10^{4}\right)$ et sont fréquemment absentes après sevrage (Gouet et Fonty 1979), alors que les bactéries anaérobies strictes restent stables à $10^{9}-10^{11}$ bactéries/g (figure 4). Le microbiote anaérobie facultatif apparaît simple, et dominé par les streptocoques jusqu'à $14 \mathrm{j}$ d'âge. Les entérobactéries apparaissent avec l'ingestion d'aliment solide (à environ 20 j). Chez le lapereau, l'absence du genre Lactobacille est originale par rapport aux autres mammifères domestiques. Les bactéries anaérobies strictes et non sporulantes, particulièrement les bacilles gram négatifs (Bacteroides) sont prévalents dans tous les segments digestifs. Les bactéries sporulées sont de 100 à 1000 fois moins nombreuses que les Bacteroides, et elles appartiennent principalement aux genres Clostridium, Endosporus et Acuformis.

Dans le côlon, la cinétique d'implantation des bactéries est similaire (Gouet et Fonty 1979). En outre, Emaldi et al (1979) ont montré que la quantité totale de bactéries est similaire dans le caecum et les cæcotrophes (environ $10^{11}$ bactéries/g), mais 10 fois plus faible dans les fèces dures.

Dès $14 \mathrm{j}$ d'âge, les bactéries amylolytiques (i.e. capable de dégrader in vitro un substrat «amidon») sont fortement implantées dans le caecum et ne diminuent pas ensuite (figure 5). Les streptocoques (S. faecium, S. faecalis) atteignent un maximum chez le lapereau de 1 à 2 semaines d'âge, puis diminuent (Gouet et Fonty 1979). Escherichia Coli est généralement absent chez le lapereau de 2 ou $3 \mathrm{j}$ d'âge ; il apparaît à 7 jours chez les lapins (Padilha et al 1995), et atteint un maximum $\left(10^{7}\right.$ bact. $\left./ \mathrm{g}\right)$ à la fin de la troisième semaine d'âge, puis chute brusquement. Ce phénomène semble indépendant du régime alimentaire, car il a été observé chez le lapereau sevré classiquement, ou bien chez le lapereau 
Figure 4. Cinétique d'implantation de quelques populations bactériennes dans le caecum du lapin en croissance, (données moyennes obtenues par culture in vitro).

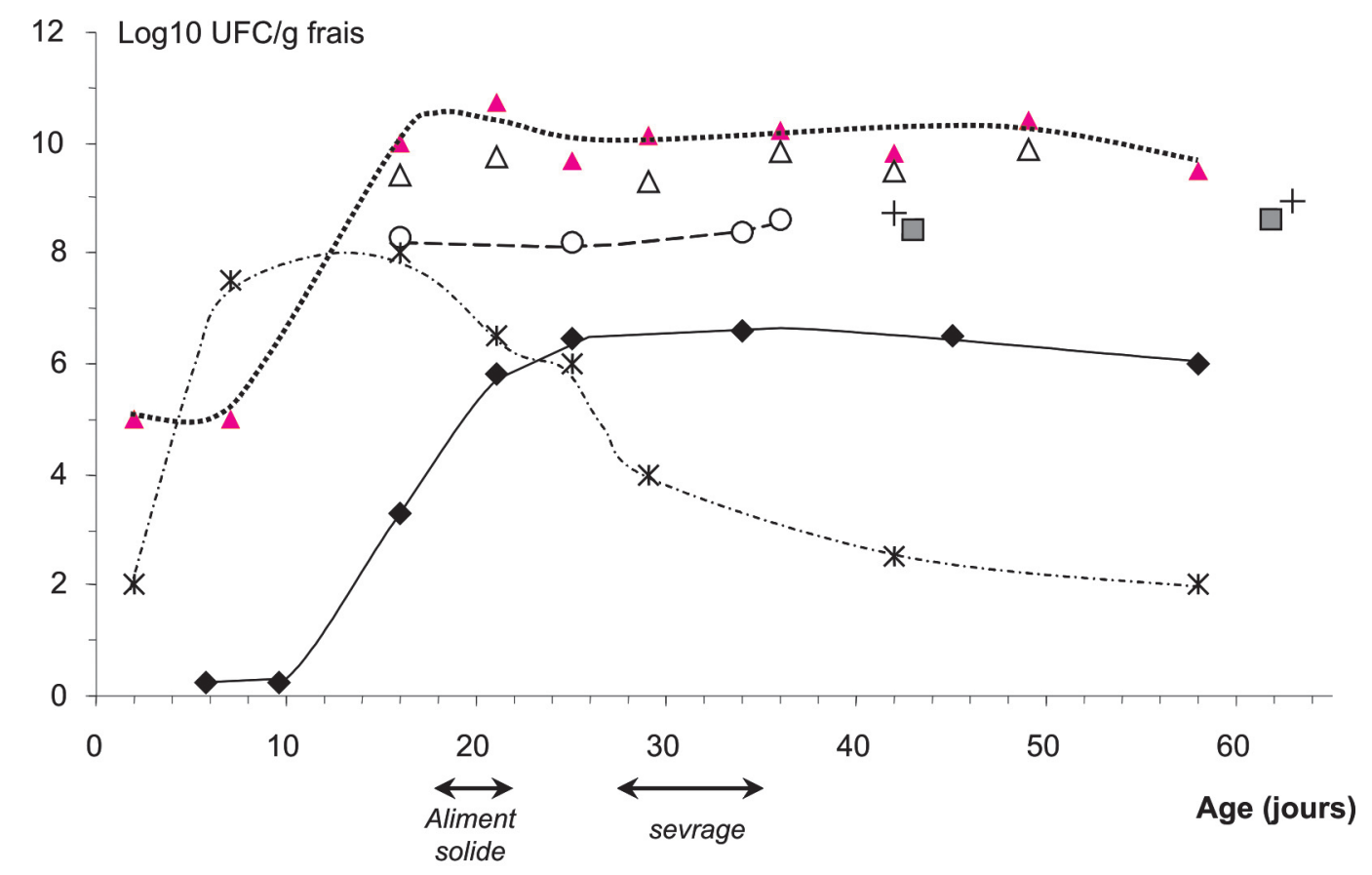

\footnotetext{
$\triangle$ Bact. anaerobies totale $\Psi$ Bact. aerobies totale $\bigcirc$ Bacteroides $\triangle$ Bact. amylolytiques

- Bact. cellulolytiques $\square$ Bact. xylanolytiques + Bact. pectinolytiques
}

Gouet et Fonty 1979, Boulharouf et al 1991, Zomborsky-Kovacs et al 2000, Gidenne et Licois 2005.

exclusivement allaité jusqu'à $42 \mathrm{j}$ (Padilha et al 1999). En fait, 10 à 20\% des lapereaux âgés de 15 à $22 \mathrm{j}$ ne seraient pas porteurs d'E. Coli $\left(<10^{2} / \mathrm{g} ; \approx 80 \%\right.$ de porteurs avec $10^{4}$ à $10^{5} \mathrm{E}$. Coli $\left./ \mathrm{g}\right)$, et cette proportion atteindrait $30 \%$ chez des lapins de 7 semaines.
Les bactéries cellulolytiques augmentent dès que l'animal ingère de l'aliment solide (vers $18 \mathrm{j}$, figure 5) pour atteindre $10^{7}$ bact./g après le sevrage (Boulahrouf et al 1991). Si les lapereaux, ne sont alimentés qu'avec du lait, les bactéries cellulolytiques ne s'implantent pas (Padilha et al 1999).

Figure 5. Equilibre entre les bactéries et les archaea dans le caecum en fonction de l'âge du lapin.

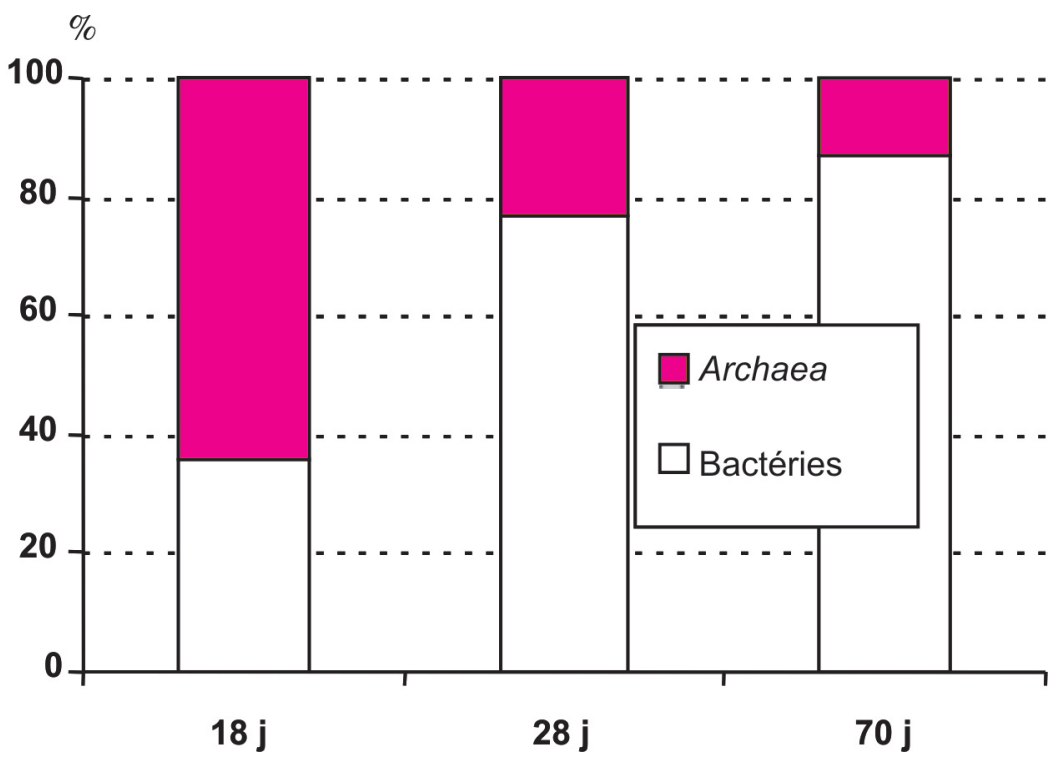

Quelques bactéries fibrolytiques ont été identifiées au niveau caecal : Eubacterium cellulosolvens et Bacteroides sp. pour la cellulolyse, Bacteroides ruminicola et Butyrivibrio fibrisolvens pour l'hydrolyse de pectines et de xylanes (Boulahrouf et al 1991). Les bactéries xylanolytiques et pectinolytiques s'implanteraient à un niveau supérieur à celui des bactéries cellulolytiques $\left(10^{8}-10^{9}\right.$ vs $10^{5}-10^{6}$, figure 4).

b) Données récentes sur la biocénose caecale, obtenues par des méthodes moléculaires

L'usage de techniques moléculaires est maintenant généralisé en microbiologie digestive. Elles permettent de mieux appréhender la complexité du microbiote, sa biodiversité et sa stabilité, notamment en fonction de facteurs alimentaires ou nutritionnels. La plupart des méthodes sont basées sur l'analyse d'une partie du génome des microorganismes (gène codant pour l'ARN ribosomal 16S). Il s'agira soit, d'identifier et de dénombrer des espèces bactériennes en détectant dans un échantillon la présence de certaines séquences d'ADN (techniques d'hybridation et de qPCR), soit de décrire une 
Figure 6. Populations bactériennes présentes dans le caecum du lapereau au sevrage (28 j) (identification par hybridation de sondes ARNr 16S).

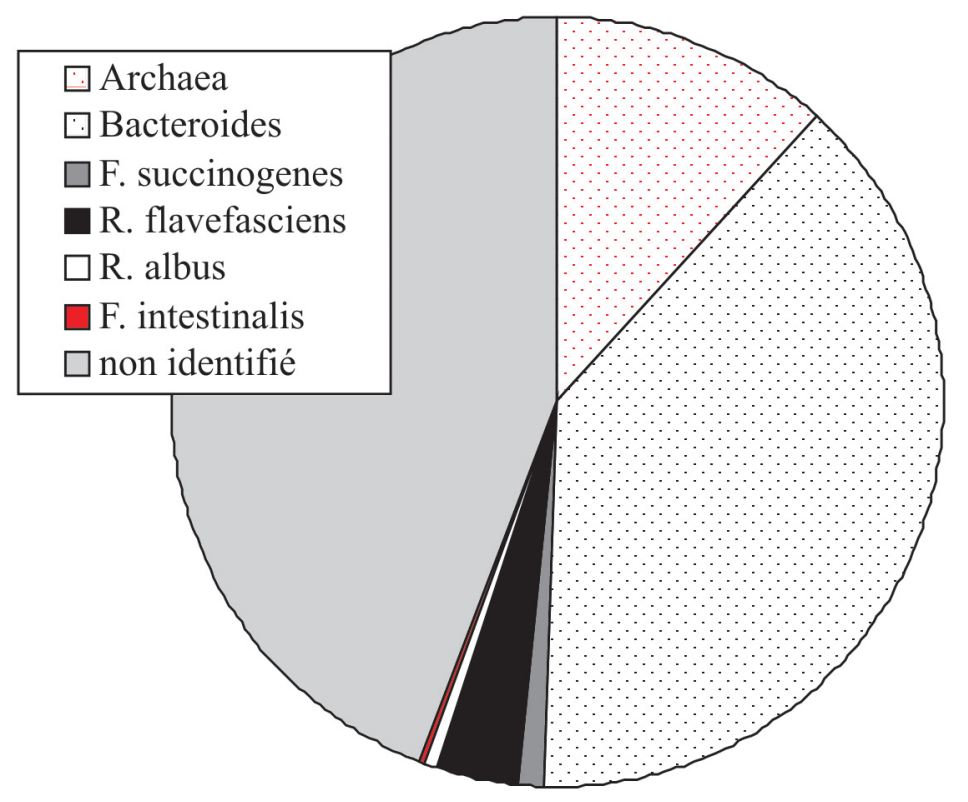

«empreinte moléculaire» des différentes populations microbiennes présentes dans l'échantillon (T-RFLP, SSCP, DGGE...) pour calculer des index de biodiversité, ou pour analyser la similarité du microbiote entre échantillons (Carabaño et al 2006).

A l'aide d'une technique d'hybridation (dot blot ARNr 16S), Bennegadi et al (2003) ont montré qu'avant sevrage (à 18 j) le microbiote total est constitué majoritairement d'archaea (> 60\%), les bactéries n'en représentant que $40 \%$; et après sevrage ( $>28 \mathrm{j})$ cet équilibre est inversé (figure 5). Ils montrent aussi la prédominance du groupe Flexibacter-Cytophaga-Bacteroides, et la présence de quatre espèces cellulolytiques, déjà identifiées dans le rumen ou le caecum du rat: Fibrobacter succinogenes, Ruminococcus albus et Ruminococcus flavefasciens (rumen) Fibrobacter intestinalis (caecum de rat) (figure 6). Cependant, ces bactéries fibrolytiques ne représentent qu'environ $5 \%$ du microbiote caecal, sachant qu'environ $40 \%$ restent non identifiés.

Un premier inventaire moléculaire des populations bactériennes caecales a été réalisé chez le lapin de 56 j par Abecia et al (2005a), et seulement une espèce bactérienne (identifiée par la séquence de l'ADNr 16S) était déjà répertoriée dans les banques de données (NCBI : http://www.ncbi.nlm.nih. gov/Genbank/index.html). Un inventaire plus complet a été réalisé récemment par Cauquil et al (2007) chez un lapin adulte. Parmi les 228 séquences d'ARNr 16S, 70 espèces bactériennes dans des écosystèmes digestifs de difféécosystèmes

$\S:$ bactéries non cultivable donnée GenBank). rents animaux (dinde, ruminant...). L'analyse phylogénétique classe ces espèces dans leur très grande majorité dans les Firmicutes (93\%), ainsi que quelques Bacteroidetes $(4,3 \%)$ et Verrucomicro-biae $(1,4 \%)$.

La biodiversité bactérienne serait similaire dans le caecum d'un lapereau de $16 \mathrm{j}$ et dans celui de sa mère (figure 8, approche T-RFLP, Garcia et al $2005)$; elle diminuerait quand les lapereaux commencent à manger de l'aliment granulé, puis augmenterait parallèlement à l'accroissement de l'ingestion. En revanche, la similarité entre le microbiote caecal de la mère et du lapereau serait faible (environ 10\%), probablement en raison de la forte différence d'alimentation (granulé vs lait). Les communautés bactériennes caecales des lapereaux d'une même portée présenteraient un degré de similarité plus élevé (47\%) que celui trouvé entre portées. Le sevrage produirait une diminution de la biodiversité caecale (2000 vs 600 séquences identifiées, TRFLP). Abecia et al (2007a) ont montré, par l'approche DGGE, qu'en cas d'adoption le microbiote caecal du lapereau est plus proche de celui de la mère allaitante, que celui de la mère biologique. Il serait donc possible de moduler dès la naissance l'implantation du microbiote. Via une approche SSCP

Figure 7. Inventaire moléculaire des bactéries caecales chez le lapin adulte : distribution des espèces bactériennes différentes, et similarité avec des bactéries de différents

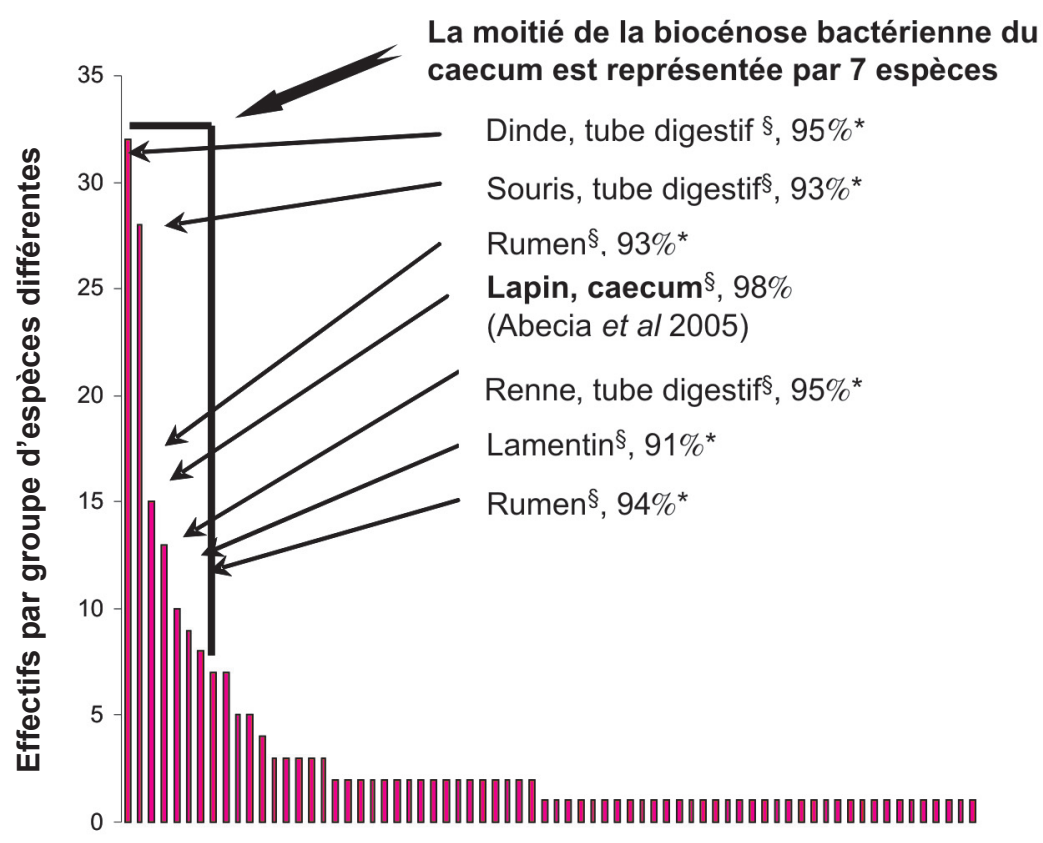

Espèces bactériennes différentes $(n=70)$

*: pourcentage de similarité avec des bactéries d'autres écosystèmes (BLAST sur la base de 
Figure 8. Biodiversité du microbiote caecal entre la femelle et sa portée (approche T-RFLP).

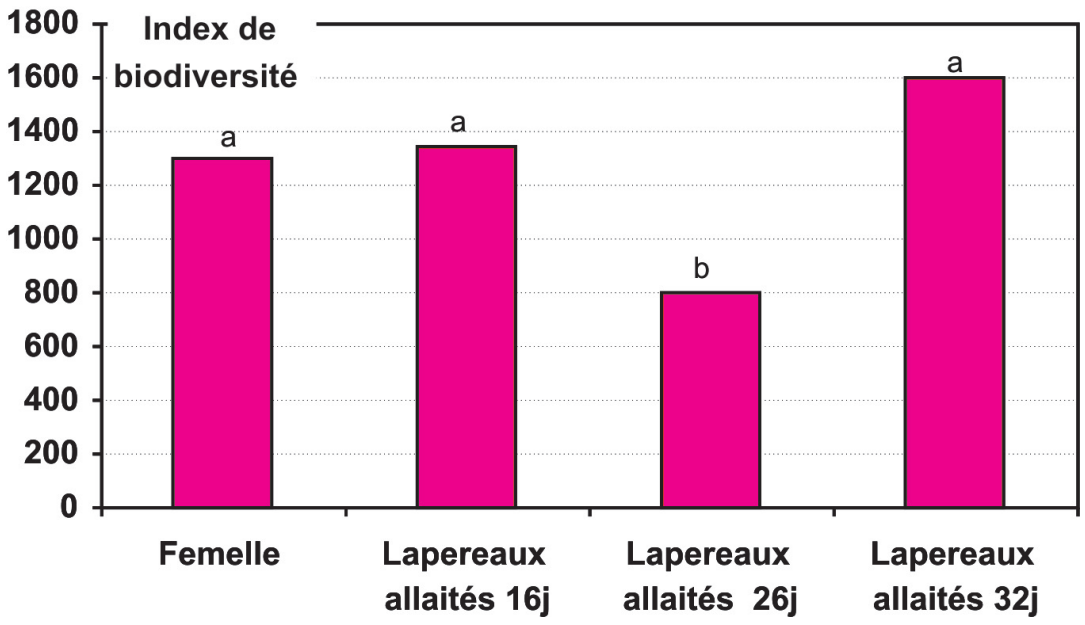

(figure 9), Michelland et al (2008b) montrent chez le lapin adulte que la diversité des communautés bactériennes est relativement stable dans le temps et entre individus. Les caecotrophes présentent une bonne similarité de composition et de diversité avec le contenu caecal, et seraient utilisables pour étudier la dynamique temporelle de la biocénose caecale.

\section{2 / Effets de quelques fac- teurs nutritionnels et ali- mentaires sur l'écosystème caecal du lapin}

\section{1 / Contrôle nutritionnel de l'écosystème caecal}

La nature et la quantité des aliments ingérés influencent l'écosystème cae- cal, car les nutriments arrivant au caecum constituent le substrat pour la biocénose. De plus, ils influencent les conditions physicochimiques du biotope, et aussi la motricité intestinale et le transit digestif. Par exemple, quelques heures de mise à jeun conduisent à une chute rapide de la concentration caecale en $\mathrm{AGV}$ et à une inversion du ratio C3:C4 (Gidenne et Bellier 1992), ce qui illustre bien la dépendance étroite entre le flux iléal de nutriments et l'activité du microbiote caecal.

a) Effets de l'ingestion de fibres et d'amidon

De nombreuses études ont montré l'effet favorable des fibres sur l'activité microbienne caecale et sur la santé digestive du lapin en croissance, (Gidenne 2003, Gidenne et Garcia 2006). L'augmentation de l'ingestion de fibres (sans modifier leur qualité), aug- mente ou n'a aucun effet sur l'activité fibrolytique bactérienne et sur la concentration caecale en AGV totaux, mais la proportion de butyrate diminue. La quantité de fibres entrant dans le caecum ne semble pas un facteur limitant pour l'activité fermentaire, car le temps de rétention caecal des digesta est relativement court (8-16 h), ce qui permet surtout la dégradation des fibres rapidement fermentescibles, telles que les pectines ou les hémicelluloses. Cependant, pour de très faibles concentrations en fibres (ADF $<10 \%)$ une augmentation de l'efficacité de la dégradation des fibres a été observée (De Blas et al 1986, Bellier et Gidenne 1996), et peut être attribuée à une rétention plus longue des digesta dans le segment caeco-colique. Par ailleurs, la concentration en fibres ne semble pas influencer l'apport énergétique provenant des fermentations caecales (Gidenne 1994). Parallèlement, on peut supposer que la concentration en fibres alimentaires module la biocénose, soit directement soit en modifiant le transit digestif. Ainsi, la hausse du taux de fibres favoriserait les bactéries cellulolytiques (Boulahrouf et al 1991) telles que Ruminococcus albus (Bennegadi et al 2003), mais aussi les archaea (au dépens des bactéries).

La qualité des fibres, en particulier leur fermentescibilité, est un facteur majeur de modulation de l'activité microbienne. Ainsi, l'ingestion de pectines ou d'hémicelluloses, dont le temps de fermentation est plus court que celui de la cellulose, stimule l'activité de la biocénose caecale : concentrations en AGV plus élevées (Garcia et al 2000, 2002, Gidenne et Bellier 2000 ,

Figure 9. Profil du microbiote bactérien réalisé à partir d'un cæcotrophe (approche SSCP).

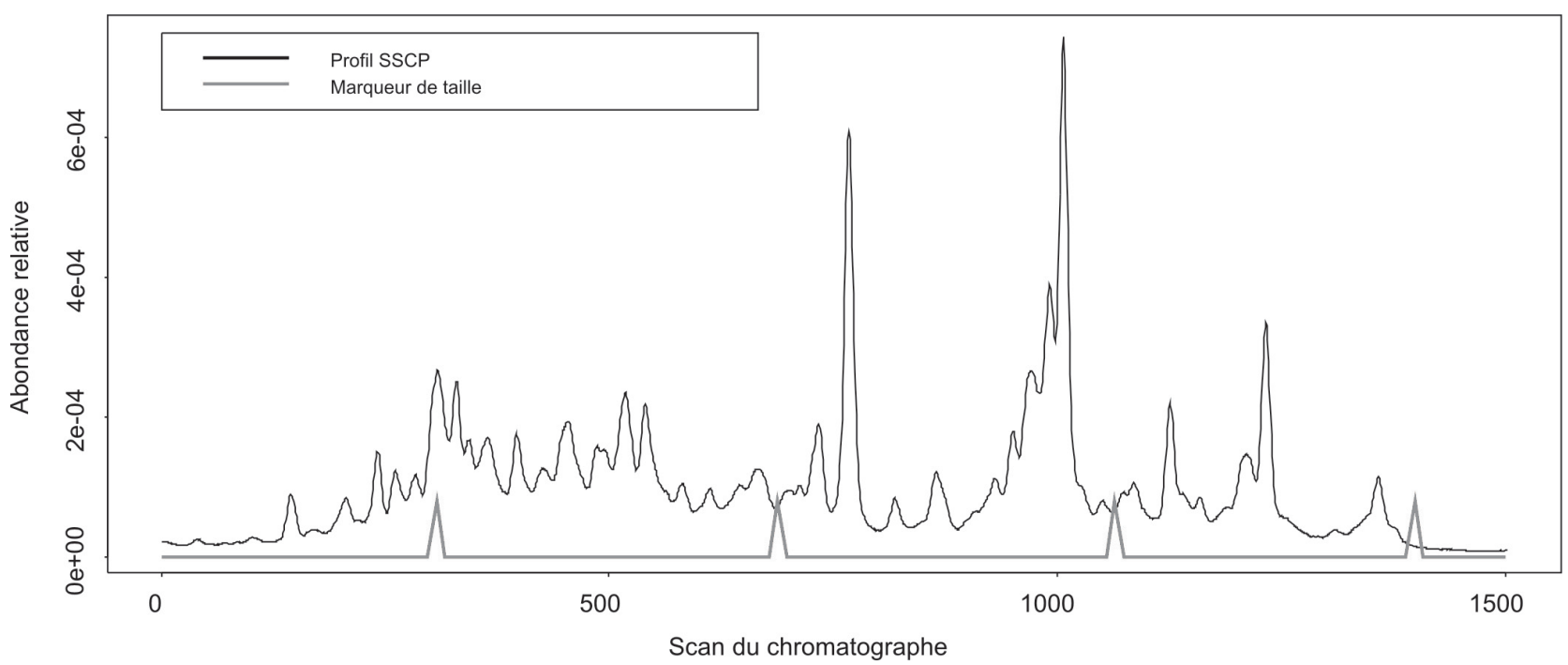

Chaque pic de la courbe noire correspond à une espèce bactérienne, ou un groupe d'espèces. 
Gidenne et al 2004a) et stabilisées plus précocement chez le lapin en croissance (Candau et al 1978), et plus forte production de biomasse bactérienne ( $+80 \%$ : Jehl et Gidenne 1996). Néanmoins, la biomasse bactérienne recyclée par la caecotrophie $(=13 \%$ de l'ingéré d'aliment) ne semble pas modifiée, ainsi que l'avait montré Garcia et al (1995). L'ingestion de NDSF (fibres solubles dans une solution de détergent neutre ; Hall et al 1997), bien que modérée dans l'alimentation du lapin, pourrait être favorable à la santé digestive du lapereau, en relation avec une modification de la biocénose caecale (Gómez-Conde et al 2007). L'apport de NDSF réduirait la proportion de lapereaux porteurs de Clostridium perfringens (bactérie opportuniste souvent associée à des pathogènes), ou porteurs pathogènes tels que Campylobacter dans l'iléon et dans le caecum (tableau 1). De même, la mortalité due à l'EEL (Entérocolite Epizootique du lapin) serait réduite avec un régime riche en NDSF (12\%). Enfin, un niveau élevé de NDSF améliorerait la morphologie et la fonctionnalité de la muqueuse intestinale et sa réponse immunitaire (Gómez-Conde et al 2007).

L'amidon non digéré dans l'intestin grêle est rapidement hydrolysé et fermenté par le microbiote caecal. Mais, même dans le cas d'un amidon fortement résistant à la digestion intestinale (fécule crue de pommes de terre incorporée à 7 et 14\%) le flux iléal d'amidon reste faible, et ne modifie pas la digestion caecale des fibres, ni l'activité fibrolytique bactérienne ou l'activité fermentaire (Pinheiro et Gidenne 2000). De même, Gidenne et al (2005) n'observent aucun effet de la nature de l'amidon (blé vs maïs vs pois) sur les fermentations caecales du lapin en croissance. L'amidon ne joue donc pas un rôle important dans le contrôle de l'activité microbienne caecale, au moins chez le lapin après sevrage $(>6$ semaines d'âge). Néanmoins, chez le lapereau, puisque la digestion de l'amidon est encore incomplète, le flux iléal d'amidon pourrait être plus élevé, et pourrait peut être modifier l'écosystème caecal.

\section{b) Effets de l'ingestion de protéines}

La qualité des protéines de l'aliment affecte évidemment le flux iléal de protéines, qui seront hydrolysées puis fermentées par le microbiote caecal et converties en ammoniaque (source principale d'azote pour la protéosynthèse microbienne). La concentration en ammoniaque varie généralement entre 4 et $18 \mathrm{mM}$ dans le caecum. D'autres voies métaboliques contribuent à l'apport d'ammoniaque dans le caecum : environ $25 \%$ du pool caecal d'ammoniaque provient du catabolisme de l'urée plasmatique, absorbée par la paroi caecale (Forsythe et Parker 1985) et convertie en ammoniaque par les bactéries uréolytiques (Emaldi et al 1979, Crociani et al 1984). De plus, de l'urée (15\% du taux de dégradation) provient du flux iléal de digesta. Comparé au rumen, Carabaño et al (1988) estiment que la teneur en ammoniaque caecale n'est pas un facteur limitant pour la protéosynthèse microbienne.

L'intérêt du remplacement de protéines alimentaires végétales par des sources d'azote non protéique a été étudié chez le lapin par Salses et al (1977). Ainsi, l'urée est efficacement utilisée, mais seulement si elle est directement infusée dans le caecum. En effet, l'addition d'urée dans l'aliment est inefficace, car $90 \%$ de l'urée est absorbée avant d'atteindre le caecum (Candau et al 1980). Cependant, Makkar et al (1990) ont rapporté que l'activité cellulolytique caecale serait plus élevée pour un régime supplémenté avec de l'urée. Crociani et al (1991) ont observé la présence dans le caecum de bactéries aérobies facultatives hydrolysant le biuret, qui serait alors efficacement utilisé par le lapin en croissance.

Peu d'études ont été réalisées pour évaluer l'activité microbienne en fonction de l'ingestion de protéines. Une élévation du taux de protéine brute de l'aliment (13 à 16\%) conduit à une hausse de la concentration caecale en azote, mais l'effet sur le $\mathrm{pH}$ caecal est controversé, alors que le taux d'AGV tendrait à augmenter (Fraga et al 1984, Al Bar et Al-Aghbari 1996). Un excès de protéines favoriserait la prolifération de certains pathogènes tels que $E$. Coli qui utilisent les acides aminés comme substrat pour la croissance (Catala et Bonnafous 1979, Cortez et al 1992).

Chez le lapereau, dont les besoins protéiques sont élevés, une substitution trop importante de fibres digestibles par des protéines accroît le risque de diarrhée, ainsi que l'ont démontré Gidenne et al (2001) dans une étude multi-sites. Cet effet pourrait s'expliquer par une disponibilité plus élevée de substrats azotés dans le caecum qui favoriserait plutôt la prolifération de bactéries pathogènes (Cortez et al 1992). De même, une hausse du flux iléal de protéines augmenterait l'acidité

Tableau 1. Effet du régime sur la biodiversité bactérienne (à 35-39 j d'âge) et la détection de quelques bactéries*, et sur la mortalité du lapereau sevré précocement (25j).

\begin{tabular}{|c|c|c|c|c|c|c|c|}
\hline \multirow{2}{*}{ Essais } & \multicolumn{2}{|c|}{ Biodiversité ${ }^{\star \star}$} & \multicolumn{2}{|c|}{ Clostridium perf. * } & \multicolumn{2}{|c|}{ Autres bactéries* } & \multirow{2}{*}{ Mortalité } \\
\hline & iléon & caecum & iléon & caecum & iléon & caecum & \\
\hline $\begin{array}{l}\text { hausse du } \\
\text { taux de NDF } \\
(25 \text { vs } 30 \%)\end{array}$ & baisse & hausse & NS & NS & $\begin{array}{l}\text { baisse de } \\
\text { Bacteroides }\end{array}$ & $\begin{array}{c}\text { hausse de } \\
\text { Bacteroides et } \\
\text { de } \\
\text { Ruminococus }\end{array}$ & baisse \\
\hline $\begin{array}{l}\text { hausse du taux de } \\
\text { NDSF (8 vs 12\%) }\end{array}$ & NS & NS & NS & baisse & $\begin{array}{c}\text { baisse de } \\
\text { Campylobacter }\end{array}$ & $\begin{array}{c}\text { baisse de } \\
\text { Campylobacter }\end{array}$ & baisse \\
\hline $\begin{array}{l}\text { hausse du taux de } \\
\text { protéines brutes } \\
(16 \text { vs 18\%) }\end{array}$ & baisse & NS & baisse & NS & $\begin{array}{c}\text { baisse de } \\
\text { Campylobacter }\end{array}$ & & baisse \\
\hline $\begin{array}{l}\text { nature des protéines } \\
\text { (luzerne vs «soja } \\
+ \text { fibres») }\end{array}$ & NS & NS & NS & NS & $\begin{array}{c}\text { baisse de } \\
\text { Clostridium spp. }\end{array}$ & & NS \\
\hline
\end{tabular}

\footnotetext{
** : index de biodiversité calculé selon une approche T-RFLP (Badiola et al 2004).

* : présence de profil compatible (séquence d'ADN) détectée par T-RFLP.

NS : sans effet.

NDSF : Neutral Detergent Soluble Fibre.
} 
caecale (Gutierrez et al 2003, Nicodemus et al 2003, Gómez-Conde et al 2007), et pourrait favoriser certaines espèces comme les clostridies (tableau 1). Ce phénomène serait plus fréquent chez le lapereau dont la maturation digestive intestinale est inachevée.

\section{c) Effets de l'ingestion de lipides}

L'alimentation du lapin contient peu de lipides (1 à 4\%), qui de plus sont fortement digérés avant le caecum. Quelques études ont néanmoins analysé l'effet des lipides alimentaires sur l'activité microbienne caecale. La digestibilité des fibres semble améliorée lors d'addition de lipides dans l'alimentation (Santoma et al 1987, Fekete et al 1989, Falcao E Cunha et al 1996), tandis que le caecum serait plus développé et son contenu plus élevé (Falcao E Cunha et al 1996). En outre, on a récemment constaté (in vitro) que certains acides gras à chaîne moyenne, tels que l'acide caprylique et caprique (sous la forme de triacylglycérol), possédaient une activité antimicrobienne sur certaines bactéries caecales (Marounek et al 2002), et auraient un effet favorable sur la santé digestive du lapin en croissance (Skrivanova et Marounek 2005). Cependant, Gallois et al (2008a) n'ont pas trouvé d'effet significatif d'une addition de triglycérides à châ̂nes moyennes $(+2 \%$ d'un mélange de $\mathrm{C} 8$ et de C10) sur la santé digestive du lapereau, ni sur l'activité fibrolytique bactérienne ou le profil fermentaire caecal.

d) Nutrition et biodiversité bactérienne du microbiote intestinal

L'effet des fibres et des protéines sur le microbiote intestinal a été exploré avec une approche moléculaire (TRFLP, Badiola et al 2004), chez le lapereau sevré précocement (à $25 \mathrm{j}$ ), et recevant ou non une antibiothérapie dans un contexte d'épidémie d'EEL (Chamorro et al 2007, Gómez-Conde et al 2007). Pour 2 essais, une mortalité plus faible a été observée avec un régime plus fibreux (25 vs 30\% NDF, ou avec 8 vs 12\% NDSF, tableau 1), associée dans un cas avec une réduction de la détection de Clostridium perfringens. De même, la hausse du taux de protéines réduit la mortalité par EEL et la fréquence de Clostridies. Cependant, la localisation intestinale de cette bactérie diffère selon l'étude : au niveau iléal pour l'essai «taux de protéines», et au niveau caecal pour l'essai «type de fibres». De même, les bactéries pathogènes opportunistes adhérentes à la muqueuse intestinale, telles que $E$. Coli, Campylobacter, Yersinia ou Helico-bacter, semblent être plus sensibles aux changements du régime quand l'échantillon est pris dans l'iléon, plutôt que dans le caecum. Ces données soulignent donc que les effets du régime sur le microbiote pourraient dépendre du segment digestif.

\section{2 / Stratégies d'alimentation et contrôle de l'écosystème caecal}

Les techniques d'élevage qui influencent le comportement alimentaire modulent indirectement les fonctions digestives. Ainsi, l'âge au sevrage ou l'application de programmes de rationnement influence directement la résistance du lapereau aux troubles digestifs (Gallois et al 2007, Gidenne et al 2008). L'emploi de probiotiques ou d'antibiotiques sont des stratégies fréquentes pour lutter contre les troubles digestifs du lapereau, bien que leurs effets sur la biocénose fassent l'objet de peu de publications scientifiques.

a) Effet de l'âge au sevrage et du profil d'ingestion «lait vs aliment solide»

Chez le lapereau, l'ingestion d'aliment solide (granulé) est inversement corrélée avec la consommation de lait, ce qui modifie la maturation digestive. Ainsi, rappelons que tant qu'un lapereau est exclusivement nourri avec du lait (jusqu'à 42 j), l'implantation des bactéries fibrolytiques caecales est bloquée, et le profil fermentaire est spécifique d'une activité protéolytique majoritaire, avec : un niveau d'NH3 élevé, une faible concentration en $\mathrm{AGV}(<10 \mathrm{mM})$ et un pH élevé $(>6$, Padilha et al 1999). De même, Zomborszky-Kovács et al (2000) ont rapporté un développement plus lent de l'activité microbienne caecale chez le lapereau en double allaitement, comparé à un allaitement simple. Inversement, un sevrage précoce ou une faible ingestion de lait, stimule l'ingestion d'aliment solide et conduit à une concentration plus élevée en $\mathrm{AGV}$ et à un $\mathrm{pH}$ caecal inférieur (Xiccato et al 2003). Cependant, Gallois et al (2008b) n'ont pas trouvé d'effet significatif d'un sevrage précoce (21 contre 35 j) sur l'activité fibrolytique des bactéries caecales ou sur l'activité fermentaire.

\section{b) Effet du niveau d'ingestion}

Lors d'une réduction du niveau d'alimentation (100 à 60\%) pendant $20 \mathrm{j}$ après sevrage, les taux de mortalité et de morbidité sont significativement réduits (Gidenne et al 2008). De même,
Boisot et al (2003) ont montré un effet positif du rationnement chez des lapins soumis à une inoculation expérimentale de l'EEL. Cinq heures après la distribution du repas, la concentration caecale en AGV s'accroît linéairement avec le niveau de restriction (100 à 60\%). Parallèlement, le $\mathrm{pH}$ caecal diminue mais aucun changement d'activité fibrolytique bactérienne n'est décelé (Gidenne et Feugier 2008). Ceci confirme que le profil d'ingestion module l'activité du microbiote. L'ampleur des variations circadiennes d'activité pourrait être un facteur de résistance aux troubles digestifs, sachant que les mécanismes physiologiques à l'origine de cet effet favorable du rationnement restent à élucider.

Récemment, Abecia et al (2007b) ont étudié le microbiote caecal de la femelle ayant une ingestion élevée ou faible (via une taille de portée de 5 ou 9 lapereaux). Le niveau d'ingestion modifie le profil du microbiote (approche DGGE), même chez l'animal supplémenté avec

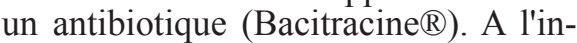
verse, le rationnement $(-25 \%)$ du lapin en croissance ne modifierait ni la diversité ni la structure de la communauté bactérienne caecale (Martignon et al 2008).

c) Contrôle du microbiote caecal par des probiotiques ou des antibiotiques

Rappelons d'abord qu'un probiotique est un additif alimentaire contenant des microorganismes (vivant ou non) qui devraient bénéficier à l'animal, par exemple en modifiant la biocénose intestinale, ou en stimulant son activité (Fooks et Gibson 2002). Un antibiotique modifie obligatoirement la biocénose puisque son rôle est d'inhiber la prolifération de certaines familles bactériennes. Mais, bien que les probiotiques et les antibiotiques soient largement utilisés en élevage cunicole, il existe très peu d'informations scientifiques vérifiées sur ce point. En revanche, de nombreuses études, récemment synthétisées par Maertens et al (2006), ont analysé l'effet potentiel de probiotiques sur la mortalité et la croissance du lapin ou sur son profil fermentaire. La littérature n'a pas rapporté d'effet significatif d'une addition de bactéries vivantes sur l'écosystème caecal, quoique l'addition de Bacillus toyoi semble réduire la population d'E. Coli (Hattori et al 1984). Les levures vivantes auraient un effet plus clair sur le microbiote intestinal, puisqu'elles pourraient augmenter le potentiel redox du caecum (Kimse et al 2008), comme cela a été observé dans le rumen de la 
vache (Marden et Bayourthe 2005). Gidenne et al (2006) signalent par ailleurs, qu'une addition de Saccharomyces cerevisiae accroît légèrement la proportion de Ruminococcus albus (bactérie cellulolytique).

L'impact de certains antibiotiques sur le microbiote caecal a fait l'objet d'études très récentes par la faculté vétérinaire de Saragosse. Ainsi, Abecia et al (2007a et b) ont constaté qu'un traitement antibiotique pourrait augmenter les différences de profils de microbiote entre les lapines, et influencerait donc celui de la portée. La Tiamuline ${ }^{\circledR}$ réduirait la biodiversité du microbiote, contrairement à la Bacitracine ${ }^{\circledR}$ qui améliore la digestibilité des fibres mais sans modification des bactéries caecale totale ni des populations cellulolytiques ou amylolytiques (Abecia et al 2005b).

\section{Conclusions et perspectives}

De nombreuses études, menées surtout par des nutritionnistes, ont concerné l'activité du microbiote intestinal et les conséquences sur la croissance ou la santé de l'animal. Cependant, chez les mammifères domestiques, le microbiote intestinal est très complexe. Durant la dernière décennie, le développement d'outils moléculaires a révolutionné les concepts de la microbiologie. Ces techniques sont en développement permanent. Elles fournissent une approche plus complète du microbiote, et permettent de nouvelles collaborations entre microbiologistes et nutritionnistes. Dans le cas du lapin, cela devrait permettre de mieux comprendre les mécanismes d'implantation de la biocénose dans le tube digestif, en relation avec la nutrition et les techniques d'élevage. Ces nouvelles connaissances permettront d'imaginer de nouvelles stratégies nutritionnelles ou d'élevage, pour améliorer la prévention des désordres digestifs chez le jeune animal.

\section{Références}

Abecia L., Fondevila M., Balcells J., Edwards J.E., Newbold C.J., Mcewan N.R., 2005a. Molecular profiling of bacterial species in the rabbit caecum. Fems Microbiol. Lett., 244, 111115.

Abecia L., Balcells J., Fondevila M., Belenguer A., Calleja L., 2005b. Effect of therapeutic doses of antibiotics in the diet on the digestibility and caecal fermentation in growing rabbits. Anim. Res., 54, 307-314.

Abecia L., Fondevila M., Balcells J., McEwan N.R., 2007a. The effect of lactating rabbit does on the development of the caecal microbial community in the pups they nurture. J. Appl. Microbiol., 103, 567-564.

Abecia L., Fondevila M., Balcells J., Lobley G.E., Mcewan N.R., 2007b. The effect of medicated diets and level of feeding on caecal microbiota of lactating rabbit does. J. Appl. Microbiol., 103, 787-793.

Adjiri D., Bouillier Oudot M., Lebas F., Candau M., 1992. Simulation in vitro, des fermentations caecales du lapin en fermenteur à flux semi-continu. 1. Rôle du prétraitement du substrat alimentaire. Repr. Nutr. Dev., 32, 351360 .

Al-Bar, A.M., Al-Aghbari, A.M., 1996. Influence of deodorase in combination with different levels of protein on rabbit feed intake, body weight, and utilisation of urea. Proc. $6^{\text {th }}$ Congr. World Rabbit Sci. Ass., Toulouse, France, $79-84$.

Badiola I., Badiola I., Pérez De Rozas Am., Roca M., Carabaño R., Gómez M., García J., De Blas C., 2004. Characterization of the microbial diversity of rabbit intestinal tract by restriction fragment length polymorphism. $8^{\text {th }}$ World Rabbit Congr., Puebla, Mexico, 746-751 (http://www.dcam.upv.es/748wrc/).

Bellier R., Gidenne T., 1996. Consequences of reduced fibre intake on digestion, rate of passage and caecal microbial activity in the young rabbit. Brit. J. Nutr., 75, 353-363.
Bennegadi N., Fonty G., Millet L., Gidenne T., Licois D., 2003. Effects of age and dietary fibre level on caecal microbial communities of conventional and specific pathogen-free rabbits. Microb. Ecol. Health Dis., 15, 23-32.

Boisot P., Licois D., Gidenne T., 2003. Feed restriction reduces the sanitary impact of an experimental reproduction of Epizootic Rabbit Enteropathy syndrom (ERE), in the growing rabbit. 10èmes Journ. Rech. Cunicole, 19-20 nov., Paris, France, 267-270.

Boulahrouf A., Fonty G., Gouet P., 1991. Establishment, counts and identification of the fibrolytic bacteria in the digestive tract of rabbit. Influence of feed cellulose content. Curr. Microbiol., 22, 1-25.

Candau M., Delpon G., Fioramonti J., 1978. Influence de la nature des glucides membranaires sur le développement anatomofonctionnel du tractus digestif du lapin. 2èmes Journ. Rech. Cunicole, 4-5 avril, Toulouse, France, 1.1-1.4.

Candau M., Fioramonti J., Touitou M., 1980. Sites de dégradation de l'urée dans le tube digestif du lapin. Proc. 2nd World Rabbit Congr., 1618 april, Barcelona, Spain, 1, 81-89.

Carabaño R., Fraga M.J., Santoma G., De Blas J.C., 1988. Effect of diet on composition of caecal contents and on excretion and composition of soft and hard feces of rabbits. J. Anim. Sci., 66 901-910.

Carabaño R. Badiola I., Licois D. Gidenne T., 2006. The digestive ecosystem and its control through nutritional or feeding strategies. In: Recent advances in rabbit sciences. Maertens L., Coudert P. (Eds), Melle, Belgium, Chapt. 4, 211228.

Catala J., Bonnafous R., 1979. Modifications de la microflore quantitative, de l'excrétion fécale et du transit intestinal chez le lapin, après ligature du canal pancréatique. Ann. Zootech., 28, 128 .

Cauquil L., Monteils V., Godon J.J., Mastin G., Combes S., Gidenne T., 2007. Inventaire moléculaire de l'écosystème caecal du lapin : résultats préliminaires. Proc. VIIème Congr. Nat. Soc. Fr. Microbiol., 30-31 mai-1er juin, Nantes, France, 1p.
Chamorro S., Gomez Conde M.S., Perez De Rozas A.M., Badiola I., Carabano R., De Blas J.C., 2007. Effect on digestion and performance of dietary protein content and of increased substitution of lucerne hay with soya-bean protein concentrate in starter diets for young rabbits. Animal, 1, 651-659.

Cools A., Jeuniaux C., 1961. Fermentation de la cellulose et absorption des AGV au niveau du caecum du lapin. Arch. Int. Physiol. Biochim. 69, 1-8.

Cortez S., Brandeburger H., Greuel E., Sundrum A., 1992. Investigations of the relationships between feed and health status on the intestinal flora of rabbits. Tierarztl. Umsch., 47, 544549

Crociani F, Biavati B., Castagnoli P., Matteuzzi D., 1984. Anaerobic ureolytic bacteria from caecal content and soft faeces of rabbit. J. Appl. Bacteriol., 57, 83-88.

Crociani F., Gioffre F., Proto V., Zani G., Minardi A., Di Francia A., 1991. Dégradation microbienne du biuret et bilan azoté chez des lapins soumis à un régime alimentaire à base de biuret. Cuni-Sci., 7, 111-119.

De Blas J.C., Santoma G., Carabaño R., Fraga M.J., 1986. Fiber and starch level in fattening rabbit diets. J. Anim. Sci., 63, 1897-1904.

Elsden S.R., Hitchcock M.W.S., Marshall R.A., Phillipson A.T., 1946. Volatile acid in the digesta of ruminants and other animals. J. Exp. Biol., 20-22, 191-202.

Emaldi O., Crociani F., Matteuzzi D., Proto V., 1979. A note on the total viable counts and selective enumeration of anaerobic bacteria in the caecal content soft and hard feces of rabbit. J. Appl. Bact., 46, 169-172.

Falcao E Cunha L., Bengala Freire J.P., Goncalves A., 1996. Effect of fat level and fibre nature on performances, digestibility, nitrogen balance and digestive organs in growing rabbits. Proc. 6 ${ }^{\text {th }}$ World Rabbit Congr., 9-12 july, Toulouse, France, 1, 157-162.

Fekete S., Hullar I., Febel H., 1989. Rabbit digestion and blood composition after fat or oil addition to the feed. J. Appl. Rabbit Res., 12 233-238. 
Fooks L.J., Gibson G.R., 2002. Probiotics as modulators of the gut flora. Brit. J. Nutr., 88, S39-S49.

Forsythe S.J., Parker D.S., 1985. Nitrogen metabolism by the microbial flora of the rabbit. J. Appl. Bacteriol., 58, 363-369.

Fortun-Lamothe L., Boullier S., 2007. A review on the interactions between gut microflora and digestive mucosal immunity. Possible ways to improve the health of rabbits. Livest. Sci., 107, 1-18

Fraga M.J., Barreno C., Carabaño R., Mendez J., De Blas J.C., 1984. Effect of amounts of fibre and protein in the diet of growth and digestive traits of rabbits. An. Inst. Nac. Invest. Agrar., Ganadera, 21, 91-110.

Gallois M., Gidenne T., Tasca C., Caubet C., Coudert C., Milon A., Boullier S., 2007. Maternal milk contains antimicrobial factors that protect young rabbits from enteropathogenic Escherichia Coli infection. Clin. Vaccine Immunol., 14, 585-592.

Gallois M., Gidenne T., Orengo J., Caubet C., Tasca C., Milon A., Boullier S., 2008a. Testing the efficacy of medium chain fatty acids against rabbit colibacillosis. Vet. Microbiol., sous presse.

Gallois M., Le Huerou-Luron I., FortunLamothe L., Lalles J.P., Gidenne T., 2008 b. Adaptability of the digestive function according to age at weaning in the rabbit: I. Effect on feed intake and digestive functionality. Animal, 2, 525-535.

Garcia J., De Blas J.C., Carabaño R., Garcia P., 1995. Effect of type of lucerne hay on caecal fermentation and nitrogen contribution through caecotrophy in rabbits. Repr. Nutr. Develop., 35, 267-275.

Garcia J., Carabano R., Perez-Alba L., De Blas J., 2000. Effect of fiber source on cecal fermentation and nitrogen recycled through cecotrophy in rabbits. J. Anim. Sci., 78, 638-646.

Garcia J., Gidenne T., Falcao E Cunha L., De Blas C., 2002. Identification of the main factors that influence caecal fermentation traits in growing rabbits. Anim. Res., 51, 165-173.

Garcia J., Gomez Conde M.S., Chamorro S., Nicodemus N., De Blas C., Carabaño R., Perez De Rozas A., Badiola I., 2005. Proyecto INIA sobre enteropatía mucoide: Resultados sobre las investigaciones en nutrición. XXX Simp. Cunicultura, 19-20 may, Valladolid, Spain, ASESCU (Ed), 157-165.

Gidenne T., 1994. Estimation of volatile fatty acids and of their energetic supply in the rabbit caecum: effect of the dietary fibre level. VIèmes Journ. Rech. Cunicole, 6-7 déc., Paris, France, 2, 293-299.

Gidenne T., 2003. Fibres in rabbit feeding for digestive troubles prevention: respective role of low-digested and digestible fibre. Livest. Prod. Sci., 81, 105-117.

Gidenne T., Bellier R., 1992. Etude in vivo de l'activité fermentaire caecale chez le lapin. Mise au point et validation d'une nouvelle technique de canulation caecale. Repr. Nutr. Develop., 32, 365-376.

Gidenne T., Bellier R., 2000. Use of digestible fibre in replacement to available carbohydrates Effect on digestion, rate of passage and caecal fermentation pattern during the growth of the rabbit. Livest. Prod. Sci., 63, 141-152.
Gidenne T., Garcia J., 2006. Nutritional strategies improving the digestive health of the weaned rabbit. In: Recent advances in rabbit sciences. Maertens L., Coudert P. (Eds), Melle, Belgium, 229-238.

Gidenne T., Feugier A., 2008. Feed restriction strategy in the growing rabbit: 1- Impact on digestion, rate of passage and microbial activity. Animal, soumis

Gidenne T., Licois D., 2005. Effect of a high fibre intake on the resistance of the growing rabbit to an experimental inoculation with an enteropathogenic strain of Escherichia Coli. Anim. Sci., 80, 281-288.

Gidenne T., Pinheiro V., Falcao E Cunha L. 2000. A comprehensive approach of the rabbit digestion: consequences of a reduction in dietary fibre supply. Livest. Prod. Sci., 64, 225-237.

Gidenne T., Kerdiles V., Jehl N., Arveux P., Briens C., Eckenfelder B., Fortune H., Montessuy S., Muraz G., Stephan S., 2001. An increase of dietary ratio «digestible fibre/crude protein» doe not affect the performances of the growing rabbit but reduce enteritis incidence: preliminary results of a multi-site study. 9 èmes Journ. Rech. Cunicole, Paris, France, 65-

Gidenne T., Jehl N., Lapanouse A., Segura M., 2004a. Inter-relationship of microbial activity, digestion and gut health in the rabbit: effect of substituting fibre by starch in diets having a high proportion of rapidly fermentable polysaccharides. Brit. J. Nutr., 92, 95-104.

Gidenne T., Segura M., Lapanouse A., 2005. Effect of cereal sources and processing in diets for the growing rabbit. I. Effects on digestion and fermentative activity in the caecum. Anim. Res., 54, 55-64.

Gidenne T., Bennegadi-Laurent N., Monteils V., Fonty G. 2006. Post weaning maturation of rabbit caecal microbial communities: impact of live yeast intake. Proc. $5^{\text {th }}$ Joint Meeting RRIINRA, Gastrointestinal Tract Microbiology Symposium. 21-23 june, Aberdeen, UK., Repr. Nutr. Develop., 46 (suppl. 1), S83.

Gidenne T., Combes S., Feugier A., Jehl N., Arveux P., Boisot P., Briens C., Corrent E., Fortune H., Montessuy S., Verdelhan S., 2008. Feed restriction strategy in the growing rabbit: 2 . impact on digestive health, growth and carcass characteristics Animal, soumis.

Gomez-Conde M.S., Garcia J., Chamorro S. Eiras P., Rebollar P.G., De Rozas A.P., Badiola I., De Blas J.C., Carabano R., 2007. Neutral detergent-soluble fiber improves gut barrier function in twenty-five-day-old weaned rabbits. J. Anim. Sci., 85, 3313-3321.

Gouet P., Fonty G., 1973. Evolution de la microflore digestive du lapin holoxénique de la naissance au sevrage. Ann. Biol. Anim. Biochim. Biophys., 13, 733-735.

Gouet P., Fonty G., 1979. Changes in the digestive microflora of holoxenic rabbits from birth until adullthood. Ann. Biol. Anim. Bioch. Biophys., 19, 553-566.

Gutierrez I., Espinosa A., Garcia J., Carabano R., De Blas C., 2003. Effect of protein source on digestion and growth performance of earlyweaned rabbits. Anim. Res., 52, 461-471.

Hall M.B., Lewis B.A., Van Soest P.J., Chase L.E., 1997. A simple method for estimation of neutral detergent-soluble fibre. J. Sci. Food Agr., $74,441-449$
Hattori Y., Kozasa M., Brenes J., 1984. Effect of Toyocerin powder (bacillus toyoi) on the intestinal bacterial flora of rabbits. Proc. $3^{\text {rd }}$ World Rabbit Congr., 4-8 april, Rome, Italie, 2, 279-280.

Jehl N., Gidenne T., 1996. Replacement of starch by digestible fibre in the feed for the growing rabbit. 2. Consequences for microbial activity in the caecum and on incidence of digestive disorders. Anim. Feed Sci. Technol., 61, 193204

Jehl N., Martin C., Nozière P., Gidenne T. Michalet-Doreau B.,1995. Comparative fibrolytic activity of different microbial populations from rabbit caecum and bovine rumen. Proc. IV $^{\text {th }}$ Int. Symp. Nutr. Herbivores, Ann. Zootech., 44 (suppl.), 186.

Kimse M., Gidenne, T., Bayourthe C., Monteils V., 2007. Mesure du potentiel redox dans le cæcum du lapin : premiers résultats méthodologiques. 12 èmes Journ. Rech. Cunicole, 27-28 nov., Le Mans, France, 81-84.

Kimse, M., Bayourthe, V., Monteils, V., Gidenne, T., 2008. Live yeast stability in the digestive tract of the rabbit: relationship with digestion, growth and digestive health. $9^{\text {th }}$ World Rabbit Congr., Verona, Italy, 695-700 (http://world-rabbit-science.com).

Licois D., Guillot J.F., Mouline C., Reynaud A., 1992. Susceptibility of the rabbit to an enteropathogenic strain of Escherichia coli 0103 . effects of animals'age. Ann. Rech. Vet., 23, 225 232.

Maertens L., Falcao E Cunha L., Marounek M., 2006. Feed additives to reduce the use of antibiotics. In: Recent advances in rabbit sciences. Maertens L., Coudert P. (Eds), Melle, Belgium, 46, 259-265.

Makkar H.P.S., Singh B., Krishna L., 1990. Effect of feeding urea on some hydrolytic and ammonia assimilation enzymes in rabbit cecum. J. Appl. Rabbit Res., 13, 35-38.

Marden J.P., Bayourthe C., 2005. Live yeast: ruminal oxygen scavenger and $\mathrm{pH}$ stabiliser. Feed Mix, 13, 2-4.

Martignon M., Combes S., Gidenne T., 2008. Effect of age and feed intake level on structure and diversity of cæcal bacterial community of the young rabbits. Proc. $6^{\text {th }}$ Joint Meet. RRIINRA, Gastrointestinal Tract Microbiology Symp., 18-20 june, Clermont-Ferrand, France.

Marounek M., Skrivanova V., Savka O., 2002. Effect of caprylic, capric and oleic acid on growth of rumen and rabbit caecal bacteria. J. Anim. Feed Sci., 11, 507-516.

Michelland R, Combes S, Cauquil L, Gidenne T, Monteils V., Fortun-Lamothe L., 2008a. Comparative study of archaeal community in the digestive ecosystem of the rabbit and cow reveals strong host species and compartment effects. Proc. $6^{\text {th }}$ INRA-RRI Symp., Gut Microbiome. Functionality, interaction with the host and impact on the environment, ClermontFerrand, France, 50.

Michelland R., Combes S., Cauquil L. Gidenne T., Monteils V., Fortun-Lamothe L., 2008b. Characterization of bacterial communities in cæcum, hard and soft feces of rabbit using $16 \mathrm{~S}$ rRNA genes capillary electrophoresis single-strand conformation polymorphism (CE-SSCP). Proc. 9 ${ }^{\text {th }}$ World Rabbit Congr., Verona, Italy, 1025-1030 (http://world-rabbitscience.com/WRSA-Proceedings/Congress2008-Verona/Verona-2008-a.htm). 
Nicodemus N., Gomez Conde M.S., Espinosa A., Garcia J., Carabaño R., De Blas C., 2003. Efecto de la utilización de bacitracina de zinc y sulfato de apramicina sobre la digestión en gazapos destetados precozmente. Proc. XXVIII Symp. Cunicultura, 2-4 april, Alcañiz, Spain. ASESCU publ., 163-170.

Padilha M.T.S., Licois D., Gidenne T., Carré B., Fonty G., 1995. Relationships between microflora and caecal fermentation in rabbits before and after weaning. Reprod. Nutr. Develop., 35, 375-386.

Padilha M.T.S., Licois D., Gidenne T., Carré B., 1999. Caecal microflora and fermentation pattern in exclusively milk-fed young rabbits. Reprod. Nutr. Develop., 39, 223-230.

Peeters J.E., Maertens L., 1988. L'alimentation et les entérites post-sevrage. Cuniculture, 83, 224-229.

Piattoni F., Maertens L., Demeyer D., 1996. In vitro study of the age-dependent caecal fermentation pattern and methanogenesis in young rabbits. Reprod. Nutr. Develop., 36, 253-261.
Pinheiro V., Gidenne T., 2000. Substitution of wheat by potato starch for growing rabbits: effect on performances, digestion and health. Proc. $7^{\text {th }}$ World Rabbit Congr., A. Blasco (Ed.), 5-7 july, Valencia, Spain, World Rabbit Sci., 8 (suppl.1), C, 391-399.

Sabatakou O., Xylouri-Frangiadaki E., Paraskevakou E., Papantonakis K., 1999. Scanning electron microscopy of large intestine (caecum and colon) of rabbit during foetal and post-natal life. J. Submicroscopic Cytol. Pathol., $31,231-236$

Salses A., Crampes F., Raynaud P., 1977. Détermination de la valeur alimentaire de l'urée donnée en perfusion intra-caecale chez le lapin. Ann. Biol. anim. Bioch. Biophys. 17, 559-565.

Santoma G., De Blas J.C., Carabaño R., Fraga M.J., 1987. The effects of different fats and their inclusion levels in diets for growing rabbits. Anim. Prod., 45, 291-300.

Skrivonova E., Marounek M., 2005. A note on the effect of triacylglycerols of caprylic and capric acid on performance, mortality and digestibility of nutrients in young rabbits. Anim. Feed Sci. Technol., 127, 161-168.
Suau A., Bonnet R., Sutren M., Godon J.J., Gibson G.R., Collins M.D., Dore J. 1999. Direct analysis of genes encoding 16S rRNA from complex communities reveals many novel molecular species within the human gut. Appl. Environ. Microbiol., 65, 4799-4807.

Xiccato G., Trocino A., Sartori A., Queaque P.I., 2003. Effect of weaning diet and weaning age on growth, body composition and caecal fermentation of young rabbits. Anim. Sci., 77, 101111.

Yu B., Chiou P.W.S., 1997. The morphological changes of intestinal mucosa in growing rabbits. Lab. Anim., 31, 254-263.

Zomborszky-Kovacs M., Gyarmati T., Parizs T., Szendrõ Z., Kametler L., Toth A., 2000. Some physiological properties of the digestive tract in traditionally reared and exclusively milk-fed young rabbits. Proc. $7^{\text {th }}$ World Rabbit Congr., A. Blasco (Ed.), 5-7 july, Valencia, Spain, World Rabbit Sci., 8 (suppl.1), C, 499-506.

\section{Résumé}

Herbivore et monogastrique, le lapin héberge dans les parties distales de son tube digestif un microbiote dense et actif qui joue un rôle clé dans sa physiologie digestive, tant du point de vue de sa santé que du point de vue de l'efficacité digestive. L'écosystème cæeco-colique est le siège d'interactions complexes entre le biotope et la biocénose, et son fonctionnement demeure encore mal connu.

Cette synthèse résume d'abord les données concernant le biotope caecal et ses caractéristiques physicochimiques, qui ont fait l'objet de nombreuses études. Nos connaissances sur la biocénose caecale, obtenues par les méthodes classiques de culture seront ensuite présentées, puis celles obtenues récemment à l'aide d'outils de microbiologie moléculaire.

Enfin, cette revue décrit les effets des principaux nutriments et de quelques stratégies d'alimentation sur le fonctionnement de cet écosystème, et les interactions avec la santé digestive du lapereau.

\section{Abstract}

The caecal ecosystem and the nutrition of the rabbit: interaction with digestive health

The rabbit, which is herbivorous and monogastric, harbours in distal parts of the gut an active and abundant symbiotic microbiota, which plays a key role in its digestive physiology, both for health and digestive efficiency. In the caeco-colic ecosystem, there are complex interactions among the biotope (i.e. the caecum) and the biocenosis (the microbiota), and its functioning still remains poorly known.

This review will first summarise the data concerning the caecal biotope and its physico-chemical characteristics, which were subjected to numerous studies. Our knowledge of the caecal biocenosis, obtained by traditional culture based methods will then be presented, and then those obtained recently using molecular microbiology tools. Lastly, this review will described the effect of some main nutrients and of some feeding strategies on the function of this ecosystem, and the relationships with the digestive health of the young rabbit.

GIDENNE T., COMBES S., LICOIS D., CARABAÑO R., BADIOLA I., GARCIA J., 2008. Ecosystème caecal et nutrition du lapin : interactions avec la santé digestive. INRA Prod. Anim., 21, 239-250. 
